\title{
PP2Ac upregulates PI3K-Akt signaling and induces hepatocyte apoptosis in liver donor after brain death
}

\author{
Yan Xiong ${ }^{1,3}$ (D) Jianan Lan ${ }^{1} \cdot$ Kaixin Huang $^{1} \cdot$ Yaruo Zhang ${ }^{1} \cdot$ Lewei Zheng $^{1} \cdot$ Yanfeng Wang $^{1} \cdot$ Qifa Ye $^{1,2}$
}

Published online: 11 October 2019

(c) The Author(s) 2019

\begin{abstract}
Multiple research groups have demonstrated that the outcome of patients receiving liver grafts from brain death donors (DBD) is poorer when compared with patients receiving grafts from living donors. This might be due to an increased hepatocyte apoptosis induced after brain death (BD). In this work, we found that the activity of PP2A-Akt pathway is significantly increased in clinical donor ex vivo hepatocytes after BD by iTRAQ protein quantification analysis. The same results were confirmed in animal models. A time-dependent promotion of apoptosis was also found in DBD rabbit liver, as demonstrated by the increased levels of cleaved Caspase 3 and the decreased of Bcl-2. To further investigate the roles of PP2A and Akt in regulating apoptosis of hepatocytes after $\mathrm{BD}$, we cultivated human liver cell line $\mathrm{L} 02$ with serum deprivation and hypoxia, to simulate the ischemic and hypoxic conditions of hepatocytes in DBD. Increased apoptosis and decreased viability were observed during the time in this model. Meanwhile PP2A activity and Akt activity were respectively increased and decreased. Notably, the proportion of Akt phosphorylation at Ser473 decreased, while other known targets of PP2A (p38, JNK and ERK) were not affected in terms of protein levels or phosphorylation. These results suggested that PP2A is involved in apoptotic induction of hepatocytes after brain death by specific suppression of Akt. This discovery was further confirmed with pharmaceutical and genetic methods. Our work implied potential targets for reducing liver cell apoptosis and improving organ donor quality after BD.
\end{abstract}

Keywords Donation after brain death $\cdot$ Hepatocyte damage $\cdot$ Apoptosis $\cdot$ PP2A

Electronic supplementary material The online version of this article (https://doi.org/10.1007/s10495-019-01570-8) contains supplementary material, which is available to authorized users.

Yanfeng Wang

yanfengwang@whu.edu.cn

Qifa Ye

yqf_china@163.com

1 Zhongnan Hospital of Wuhan University, Institute of Hepatobiliary Diseases of Wuhan University, Transplant Center of Wuhan University, Hubei Key Laboratory of Medical Technology on Transplantation, Wuhan 430071, China

2 The 3rd Xiangya Hospital of Central South University, Research Center of National Health Ministry on Transplantation Medicine Engineering and Technology, Changsha 410013, China

3 Division of Transplant Immunology, Department of Pathology and Laboratory Medicine, Children's Hospital of Philadelphia and Perelman School of Medicine at the University of Pennsylvania, Philadelphia, PA 19104, USA

\section{Introduction}

There exists a vast disparity between the number of patients on transplant waiting list and that of available organs [1-4] and the main source of donor organs are from brain death (DBD) and cardiac death (DCD). Several kidney-transplant studies have revealed a consistent and significant difference in the graft survival between grafts derived from brain-dead (BD) donors and the grafts from living donors. There are more incidents of primary graft non function and poor graft survival when grafts were from BD patients than that from living donors. Animal studies showed the same tendency: BD causes deteriorated organ quality and viability for both kidney and liver [5-7]. It was hypothesized that BD has a detrimental effect on donor organ viability $[8,9]$.

Even though a number of studies have assessed the effects of BD on kidney and liver grafts viability, the mechanism by which BD induces kidney and liver injuries has not been fully clarified. It has been suggested that apoptosis after BD 
contributes strongly to organ injury [10-13]. But it is not clear yet how BD causes apoptosis.

PP2A, a serine/threonine protein phosphatases made up of three subunits $\mathrm{A}, \mathrm{B}$ and $\mathrm{C}$, is demonstrated to be involved in apoptosis. The subunit $\mathrm{A}$ is required for the formation of the trimeric complex, subunit $\mathrm{C}$ (PP2Ac) has catalytic domain [14] and $\mathrm{B}$ is the regulatory that binds with the $\mathrm{AC}$ core complex to form the heterotrimeric holoenzyme [15] and is responsible for the substrate specificity of PP2A [16]. PP2A can act on a wide range of substrates through the holoenzyme structure that contains a distinct B subunit from the families of the proteins: B (PR55), B' (B56 or PR56), B" (PR72) and B"' (PR93/PR110) [17]. Some of the most common PP2A substrates include apoptotic protein Bax, DNA repair protein ATM, tumor suppressor protein $\mathrm{pRb}$, receptor EGFR, MAPK cell signaling protein JNK and cell cycle-associated proteins CDK4, CDK9, CD16, CDC6 and $\mathrm{CDC} 25$ [16]. PP2A can not only indirectly regulate the induction of apoptosis via the dephosphorylation of cell signaling and tumor suppressor proteins such as p38, JNK, Akt and $\mathrm{Rb}$ respectively [16, 18], but can also act directly on apoptotic and anti-apoptotic proteins [19, 20]. For example, it has been shown that protein PKR promotes mitochondrial localization of the PP2A-PR61 $\alpha$ complex leading to $\mathrm{Bcl}-2$ dephosphorylation [19]. In addition, PP2A has been reported to dephosphorylate Bax and enhance its pro-apoptotic function via direct interaction with catalytic subunit PP2A/C [20].

Protein kinase B (PKB), also known as Akt, a serine/ threonine-specific protein kinase that plays a key role in glucose metabolism, apoptosis, cell proliferation, transcription and cell migration, is mainly regulated by protein kinases and protein phosphatases [21-23]; both are highly expressed in the kidney, liver, and spleen. Akt activity has been shown to be regulated by PP2A. Overexpressed-eIF3I interacts with the activated form of oncogenic Akt1 via inhibition of PP2A phosphorylation in human hepatocellular carcinoma [24], whereas the protein REDD1 enhances PP2Amediated dephosphorylation of Akt resulting in repression of mTORC1 signaling in 293T cells [25]. In addition, it has been shown that PP2A regulates p53 and Akt cooperatively leading to apoptosis evasion by neuron cells [26]. Lastly ceramide mediated vascular dysfunction in diet-induced obesity has been shown to be through dephosphorylation of the eNOS-Akt complex by PP2A [27]. Although the actions of PP2A and Akt have been well defined in the aforementioned studies, the regulation of Akt signaling in the cellular apoptosis in the donor liver from BD patients has not yet been reported.

Based on these previous findings, we suspected that BD may induce Akt inactivation and hepatocyte apoptosis through PP2A activation in donor liver from BD individuals. In the present study, we explored the effects of $\mathrm{BD}$ on hepatocyte apoptosis and possible link of Akt and PP2A with the apoptosis.

\section{Results}

\section{Brain death (BD) inactivates Akt, activates PP2A and causes liver apoptosis both in animal model and donor liver}

We first observed an induction of apoptosis in liver tissues from the DBD animal model (Fig. 1a). Compared to the sham group, Bcl-2 levels were progressively downregulated in the DBD group from 2 to $8 \mathrm{~h}$ post brain death, while cleaved-Caspase 3 was significantly elevated with total caspase- 3 remained stable. In the meantime, the activity of PP2A was significantly increased during the time in liver tissues in the DBD group while the activity of Akt showed an opposite trend (Fig. 1b). To investigate how the PP2A affect the liver apoptosis, quantitative mass spectrometry was used to analyze differentially expressed proteins in human donor liver cells collected $2 \mathrm{~h}$ or $12 \mathrm{~h}$ after brain death (Fig. 2a). Interestingly, Akt, PP2A and proteins belonging to PI3K-Akt pathway are enriched in these samples (Fig. 2b, c), suggesting that both PP2A and PI3K-Akt pathways are involved in the regulation of apoptosis in the liver tissues after brain death. Moreover, H\&E staining of 4 donor livers evidenced more apoptotic bodies (Fig. 2d black arrow) in samples harvested $12 \mathrm{~h}$ after BD in respect to the ones collected after $2 \mathrm{~h}$ (Fig. 2d). Elisa assays performed on the same samples as in Fig. 2d confirmed the increased activity of PP2A and the decreased activity of Akt in samples collected $12 \mathrm{~h}$ after $\mathrm{BD}$ in respect to $2 \mathrm{~h}$ (Fig. 2e). These observations were in accordance with the results obtained from animal samples (Fig. 1).

\section{Hypoxia and ischemia (mimic BD) induced apoptosis is dependent on Akt inactivation and PP2A activation in vitro}

Then we set up an in vitro model for further investigating the roles of PP2A and Akt in regulating apoptosis of hepatocytes after brain death. We cultivated human liver cell line L02 in starvation (with serum deprivation) and under hypoxia (low oxygen concentration), simulating the ischemic and hypoxic conditions of hepatocytes in BD patients [30].

We found that the apoptotic rate of L02 cells was markedly increased after prolonged culture in serum deprivation and hypoxia, as demonstrated by Annexin V and PI double staining (Fig. 3a, b). Cell viability was inversely correlated to the time of culture and reached statistical 
A

Animal samples
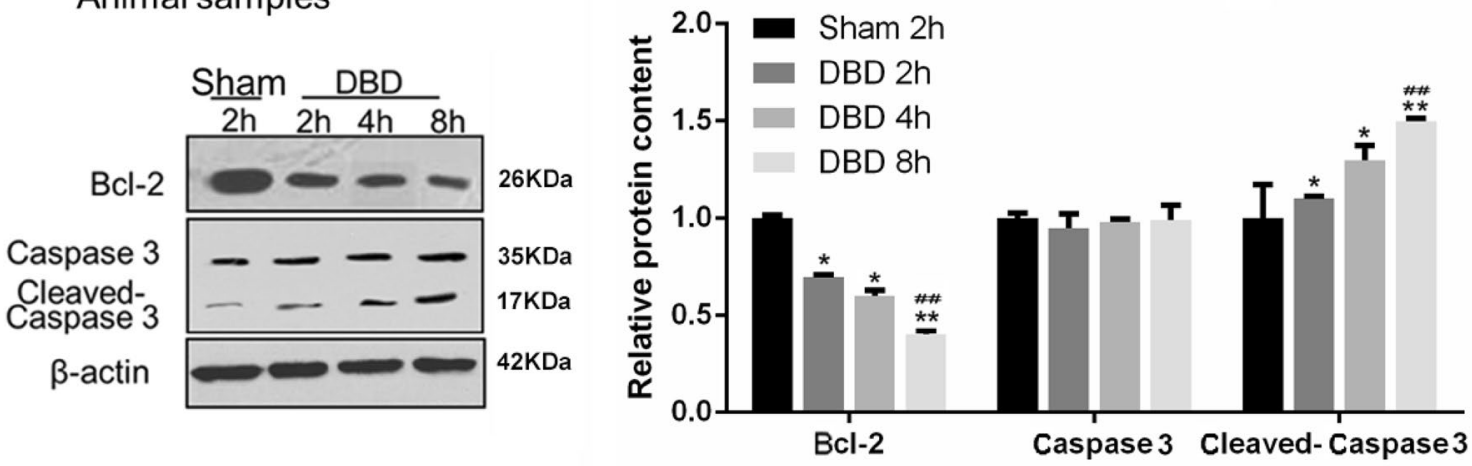

B
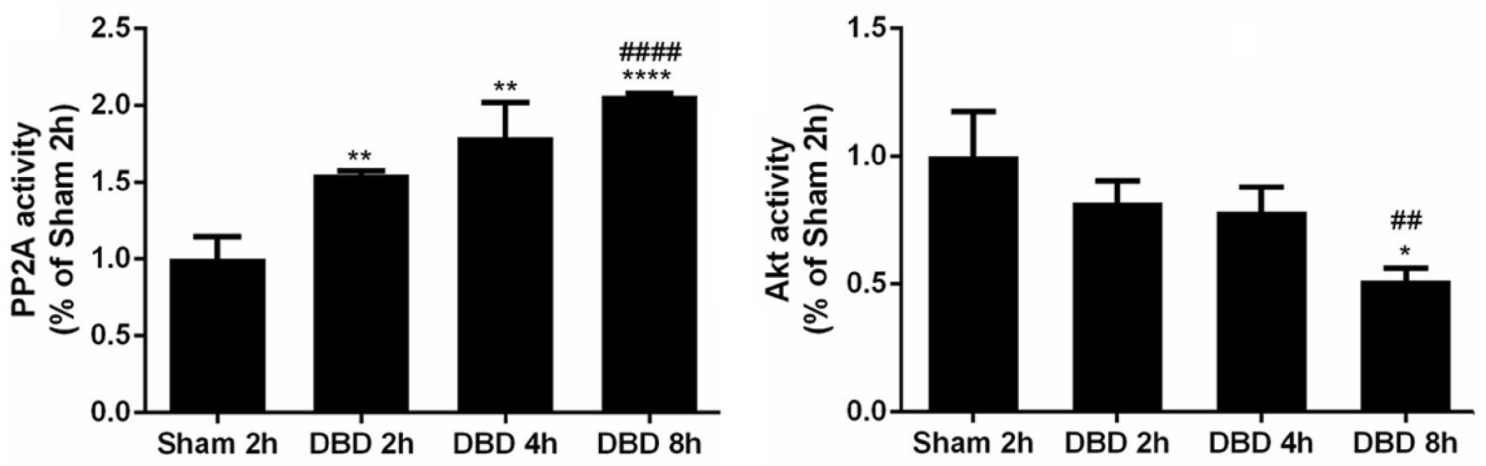

Fig. 1 Increased apoptosis as well as PP2A activation and Akt inactivation were observed in liver tissues from donation after brain death (DBD) rabbit model. The samples were harvested at $2 \mathrm{~h}, 4 \mathrm{~h}$, and $8 \mathrm{~h}$ post brain death or $2 \mathrm{~h}$ post sham operation. a The amount of apoptotic markers Bcl-2, Caspase-3 and cleaved Caspase 3 were measured by western blots. Left: representative images of western blots. Right: semi-quantitative analysis with $\beta$-actin as an internal control.

significance at $18 \mathrm{~h}$ (Fig. 3b). Moreover, the lactate dehydrogenase (LDH) levels of L02 cells increased during the induction of apoptosis (Fig. 3b). These observations confirmed that this cellular model mimics the hepatocellular impairment after brain death, with an important features of elevated apoptosis.

We also found that the activity of PP2A in L02 cells was remarkably increased over time under serum deprivation and hypoxia, while the opposite was observed for the activity of Akt (Fig. 3c). Although western blotting failed to show change in total Akt and PP2A protein level, Akt phosphorylation at Ser473 decreased during the time of hypoxia exposure, consistent with the diminishing Akt activity (Fig. 3d). For other known targets of PP2A, such as p38, JNK and ERK, the content of total protein as well as phosphorylated forms seemed not to be affected (Fig. 8). These results implied that PP2A could be involved in the regulation of hepatocytes apoptosis after brain death, possibly through dephosphorylation and inhibition of Akt activity.

The results were normalized to the Sham $2 \mathrm{~h}$ group. b The activities of PP2A and Akt were measured, as described in the "Materials and methods". The results were normalized to the Sham $2 \mathrm{~h}$ group. All data were expressed as the mean \pm SEM. $\mathrm{n}=10$ for each group. $* p<0.05, * * p<0.01$, and $* * * * p<0.0001$ versus the Sham $2 \mathrm{~h}$ group; ${ }^{\# \#} p<0.01$, and ${ }^{\# \# \#} p<0.0001$ versus the DBD 2 h group

\section{Hypoxia and ischemia (mimic BD) induced Akt inactivation is directly regulated by PP2A activation in vitro}

As hepatocytes underwent massive necrosis after $18 \mathrm{~h}$ of serum deprivation and hypoxia, we looked at the apoptotic rate of these cells after $12 \mathrm{~h}$. The treatment with AKT inhibitor (MK-2206) or activator (SC-79) [23, 31] correspondingly changed Akt activity (Fig. 4b), and respectively deteriorated or ameliorated the impairment of L02 cells under serum deprivation and hypoxia, as indicated by apoptotic rate and LDH level (Fig. 4a, b). It proved that Akt could inhibit hepatocyte apoptosis and attenuate liver cell damage upon the deficiency of nutrient and oxygen.

Furthermore, experiments with PP2A inhibitor okadaic acid (OA) [32] or its activator D-erythro-S (DES) [33] showed that altering PP2A activity would inversely affect Akt activity (Fig. 5b), demonstrating the role played by PP2A in repressing Akt signalling. On these grounds PP2A activation would induce hepatocyte apoptosis and damage 


\section{Clinical Samples}

A

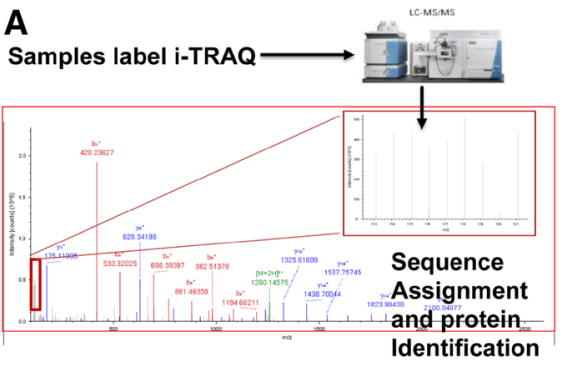

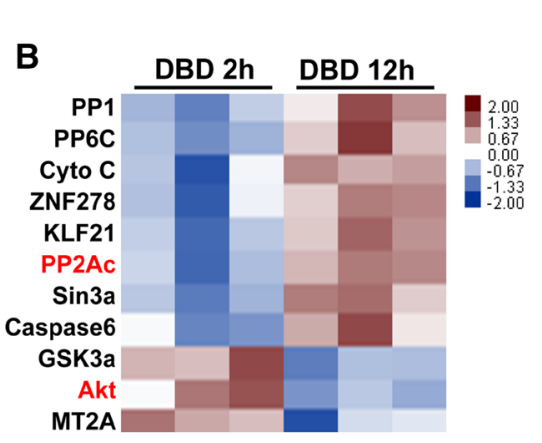

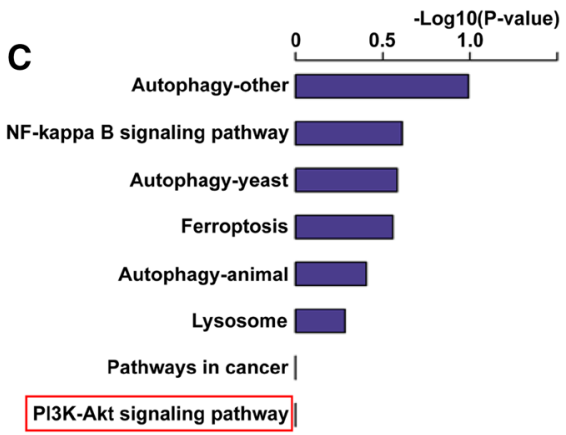

D

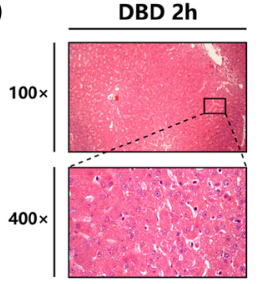

DBD 12h

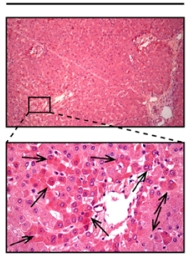

E

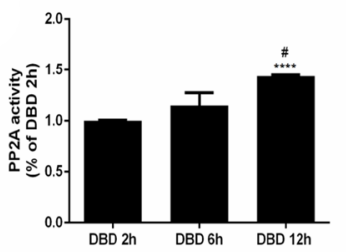

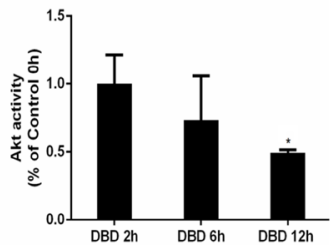

Fig. 2 PP2A activation and Akt inactivation in clinical DBD samples were observed with different time span of brain death. a Quantitative mass spectrometry was used to analyze pathway (b) and differential proteins (c) between DBD $2 \mathrm{~h}$ and DBD $12 \mathrm{~h} . \mathrm{n}=3$ for the DBD $2 \mathrm{~h}$ group and $\mathrm{n}=3$ for the DBD $12 \mathrm{~h}$ group, $\mathrm{p}$ value $<0.05$. d Representative micrographs of the liver with apoptotic bodies (black

(Fig. 5a, b) under poor nutrition and hypoxic condition. We considered that this mechanism is responsible for in vivo hepatocellular impairment in DBD.

To further verified the regulatory role of PP2A in hepatocyte apoptosis post brain death, we knockdown PP2A by using a GFP-tagged pp2ac siRNA (siPP2Ac) or we overexpressed PP2A by transfecting aRFP-tagged wildtype form of PP2Ac (wtPP2Ac) L02 cells. The transfection efficiencies of siPP2Ac or wtPP2A were confirmed by western blot analysis of PP2Ac (Fig. 9). PP2Ac knockdown significantly decreased cleaved Caspase-3 and increased Bcl-2 levels and increased the activity of Akt (Fig. 6). Overexpression of PP2Ac showed the opposite effect on cleaved Caspase-3, Bcl-2 and the activity of Akt (Fig. 7). These results further confirmed the involvement of PP2Ac in the regulation of apoptosis in liver cells under hypoxic condition through inhibiting Akt (Figs. 8, 9).

\section{Discussion}

In the present study, we revealed the involvement of PP2A in the induction of apoptosis in liver cells after brain death, by negatively regulating Akt activity. Suffering from undernourished and hypoxic conditions, the hepatocytes showed an increase in PP2A activity, which afterwards suppressed arrows) are shown by $\mathrm{H} \& \mathrm{E}$ staining at a magnification of $\times 100$ (uper) and $\times 400$ (bottom). e The results were normalized to the DBD $2 \mathrm{~h}$ group. All data were expressed as the mean \pm SEM. $\mathrm{n}=9$ for the DBD $2 \mathrm{~h}$ group, $\mathrm{n}=5$ for the DBD $6 \mathrm{~h}$ group and $\mathrm{n}=6$ for the DBD $12 \mathrm{~h}$ group. ${ }^{*} p<0.05$ and $* * * * p<0.0001$ versus the DBD $2 \mathrm{~h}$ group; $\# p<0.05$ versus the DBD 6 h group

Akt activity but had little effect on the p38, JNK or ERK signaling. The inhibition of Akt activity may be the result of decreased phosphorylation at Ser473. Apoptosis level in the damaged hepatocytes were promoted as a consequence of such "PP2A activation-Akt inhibition" axis, and pharmaceutical targeting of PP2A or Akt could correspondingly worsen or attenuate the hepatocellular damage.

Brain death (BD) is defined as the irreversible cessation of all brain activities, including that in the brain stem. Clinical and experimental studies have shown that BD is a complex pathological process that damage organ morphology and function [34-36]. The physiological changes that occur after BD include hemodynamic changes, blood coagulation, endocrine and/or electrolyte disorders. Several studies have shown that grafts from BD donors have a lower short- and long-term posttranslational effectiveness and higher incidences of primary graft non-function [37] and higher incident of acute rejection [38], in comparison with that from living donors. Despite these crucial observations, the exact etiology of the poor quality of donor-liver function has not been fully examined.

Novitzky et al. reported that BD leads to hemodynamic changes, characterized by a dramatic increase in both systolic and diastolic blood pressure [39]. These effects lead to tachycardia and the cardiac output is increased by $30 \%$, whereas a $50 \%$ increase is noted in the peripheral vascular 
A

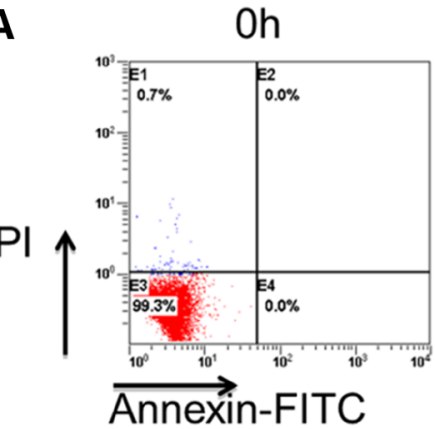

$6 \mathrm{~h}$

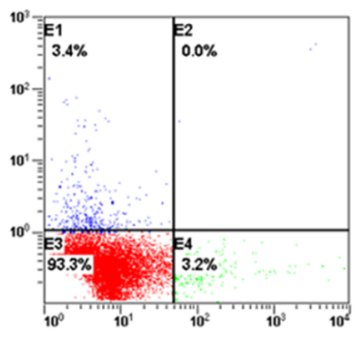

$12 \mathrm{~h}$

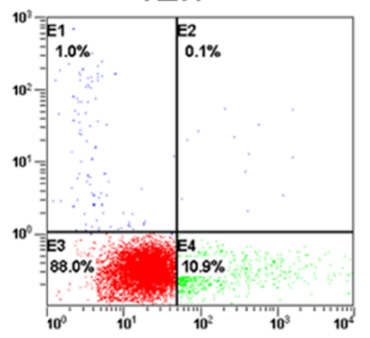

$18 \mathrm{~h}$

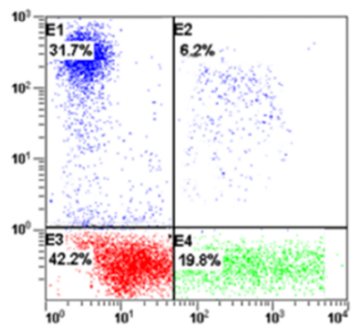

B
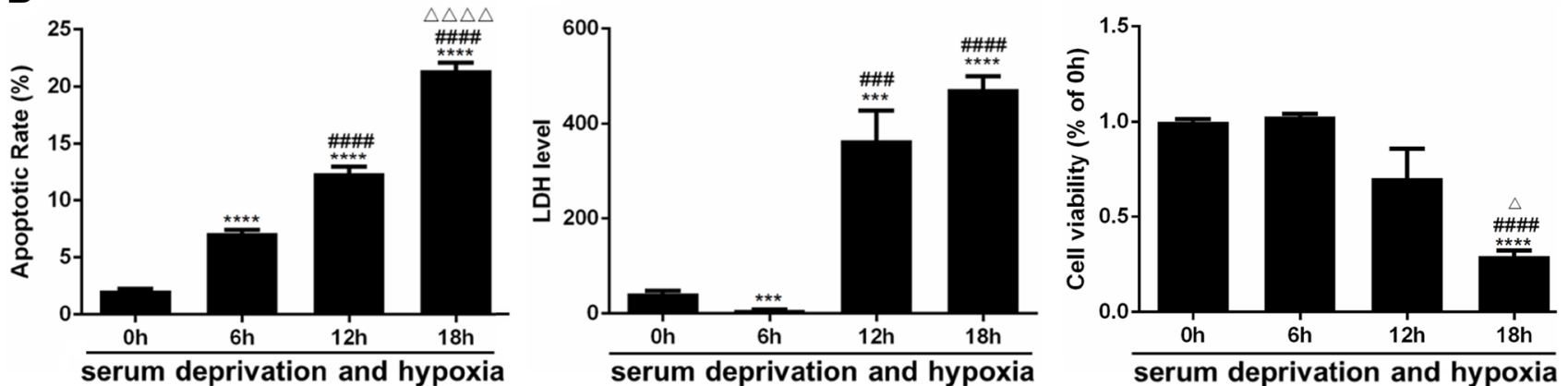

serum deprivation and hypoxia

serum deprivation and hypoxia
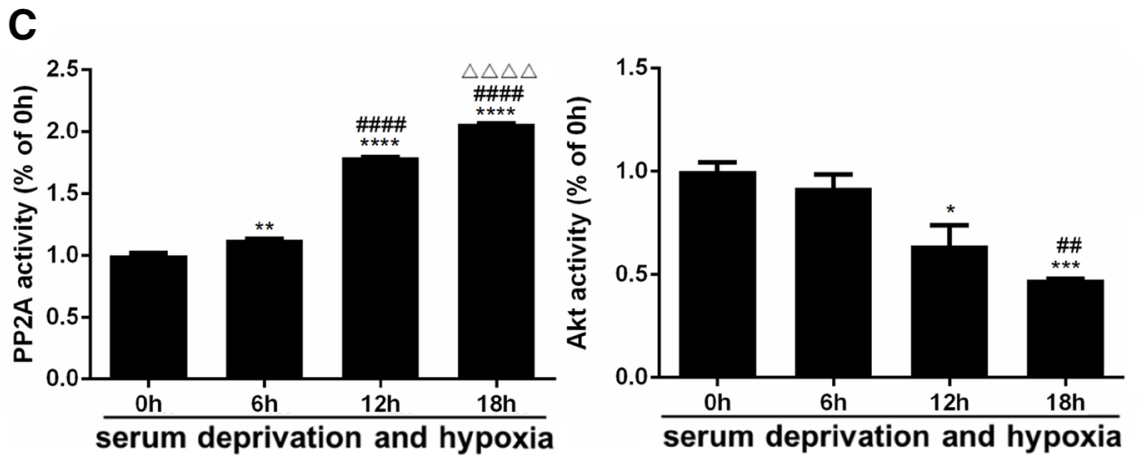

D

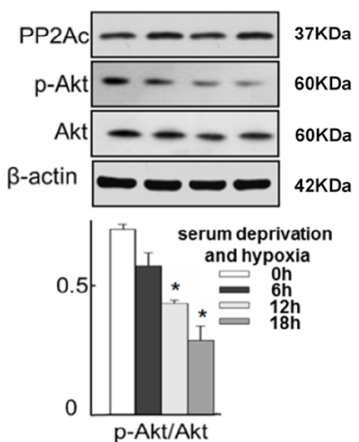

Fig. 3 Increased apoptosis and impaired viability were observed together with PP2A activation and Akt inactivation in L02 cells cultivated with serum deprivation and hypoxia (simulating the ischemic and hypoxic conditions of hepatocytes in BD individuals). The measurements below were performed at $0,6,12$ and $18 \mathrm{~h}$ exposure of serum deprivation and hypoxia. a Fluorescence-activated cell sorting (FACS) after Annexin V and PI double staining was used to detect the apoptosis rate. Representative FACS plots were shown with the right lower quadrant indicating apoptosis and the upper left quadrant indicating necrosis. b Left: quantitative analysis of the apoptotic rate. Middle: hepatocellular function reflected by lactate dehydrogenase

resistance [39]. The blood flow in the portal vein and the hepatic tissue has been reported to be approximately $40 \%$ of that corresponding to the hypotensive state in the absence of brain death [8] leading to hepatic hypoxia. In the present study, hypoxia and ischemia were induced at the cellular level for the time periods of $0 \mathrm{~h}, 6 \mathrm{~h}, 12 \mathrm{~h}$ and $18 \mathrm{~h}$, in order to mimic hepatic ischemia induced by brain death.

Several reports showed that the increased rate of apoptosis is one of the main factors that lead to poor liver graft
(LDH) level; the unit: U/L. Right: cell viability measured with CCK8 assay. c The activities of PP2A and Akt were measured with the results normalized to the $2 \mathrm{~h}$ group. $\mathbf{d}$ The total amount and phosphorylation level at Ser473 of Akt together with total amount of PP2Ac were measured by western blots. Top: representative images of western blots. Bottom: Semi-quantitative analysis with $\beta$-actin as internal control. The results were normalized to the $2 \mathrm{~h}$ group. All data were expressed as the mean \pm SEM. $n \geq 3$ for each group in each measurement. $* \mathrm{p}<0.05, * * \mathrm{p}<0.01, * * * \mathrm{p}<0.001$ and $* * * * \mathrm{p}<0.0001$ versus the $0 \mathrm{~h}$ group; ${ }^{\# \#} \mathrm{p}<0.01,{ }^{\# \#} \mathrm{p}<0.001$, and ${ }^{\# \# \#} \mathrm{p}<0.0001$ versus the $6 \mathrm{~h}$ group; ${ }^{\Delta} \mathrm{p}<0.05$, and ${ }^{\Delta \Delta \Delta \Delta} \mathrm{p}<0.0001$ versus the 12 h group

quality $[10,12,40,41]$. In our previous study, we confirmed that the increased apoptosis is the most important factor contributing to decreasing liver functions under the brain death conditions [28]. Intervention at the level of the apoptotic pathway is likely to be a promising target for drug development, in terms of improving the quality of liver graft to decrease the incident of primary graft non function and acute rejection. 


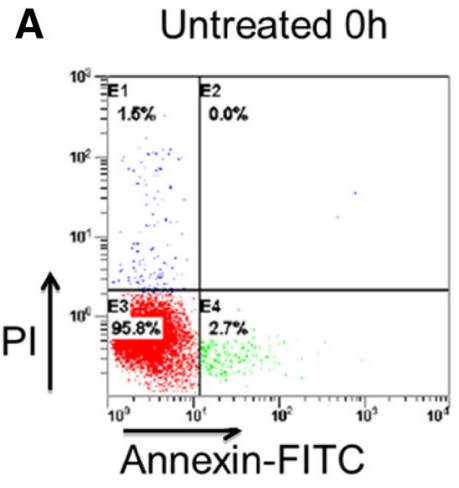

Untreated $12 \mathrm{~h}$

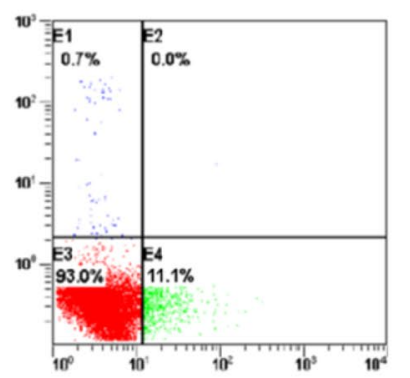

MK2206 Oh

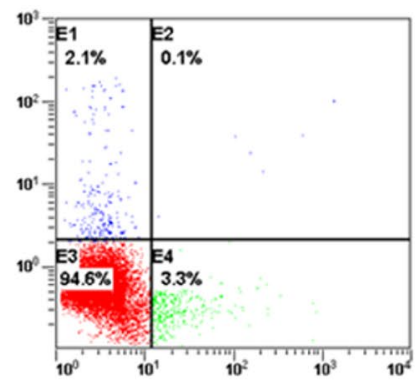

MK-2206 12h

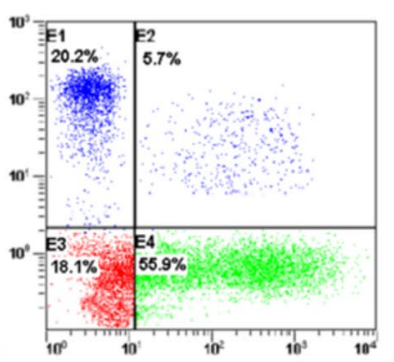

SC-79 Oh

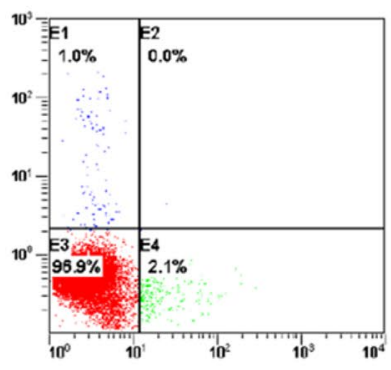

SC-79 12h

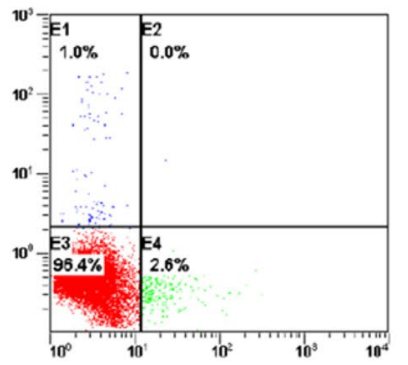

B

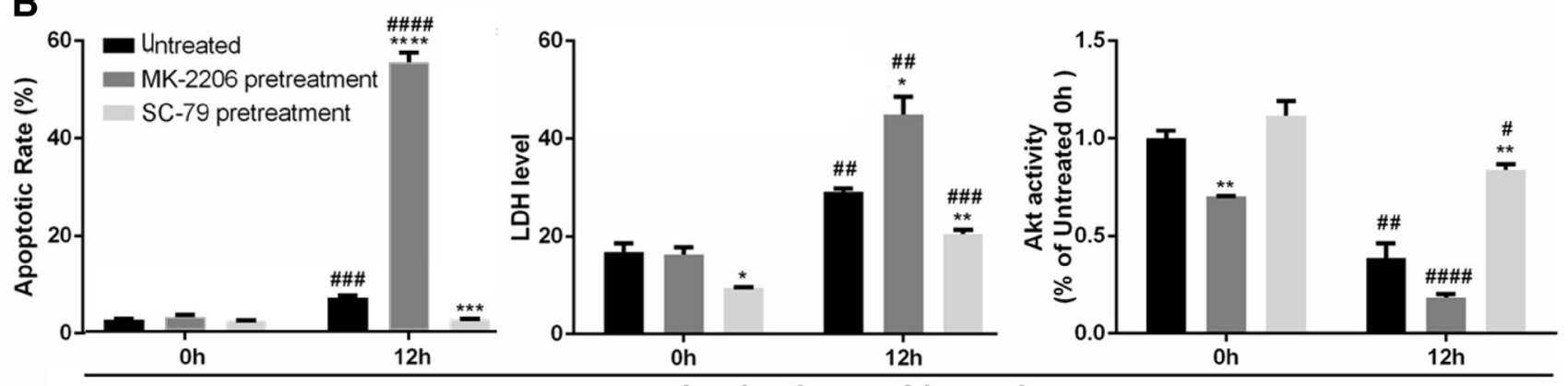

serum deprivation and hypoxia

Fig. 4 Upon MK-2206 (Akt inhibitor) pretreatment, apoptosis and cell damage were aggravated in L02 cells exposed to serum deprivation and hypoxia; while all the phenotypes were rescued to an extent upon SC-79 (Akt activator) pretreatment. MK-2206 was used at a concentration of $10 \mathrm{nM}$ and SC-79 at a concentration of $5 \mu \mathrm{M}$. The cells were pretreated with the compounds for $60 \mathrm{~min}$ before exposure to serum deprivation and hypoxia. a Representative FACS plots of apoptosis detection were shown. b Left: quantitative analy- sis of the apoptotic rate. Middle: LDH measurement; the unit: U/L. Right: the Akt activity measurement normalized to the untreated $0 \mathrm{~h}$ group. All data were expressed as the mean \pm SEM. $n=3$ for each group in each measurement. $* p<0.05, * * p<0.01, * * * p<0.001$ and $* * * * p<0.0001$ versus untreated cells at the same time; ${ }^{*} p<0.05$,

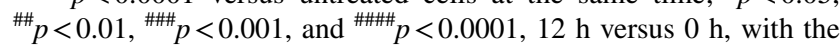
same treatment

In the current study, with the use of multiple biochemical and pharmacological approaches, we found that brain death activated PP2A and inactivated Akt in the liver. This finding was further verified with brain-death-mimic cell culture environment, in which hepatocyte apoptosis was induced. In this case PP2A activity increased and subsequently dephosphorylates Akt on ser473. PP2A is considered as a tumor suppressor enzyme that affects multiple signaling cascades such as the Ras, PI3 K, Akt and PKC pathways that have been implicated in various cancers [42]. The activation of 

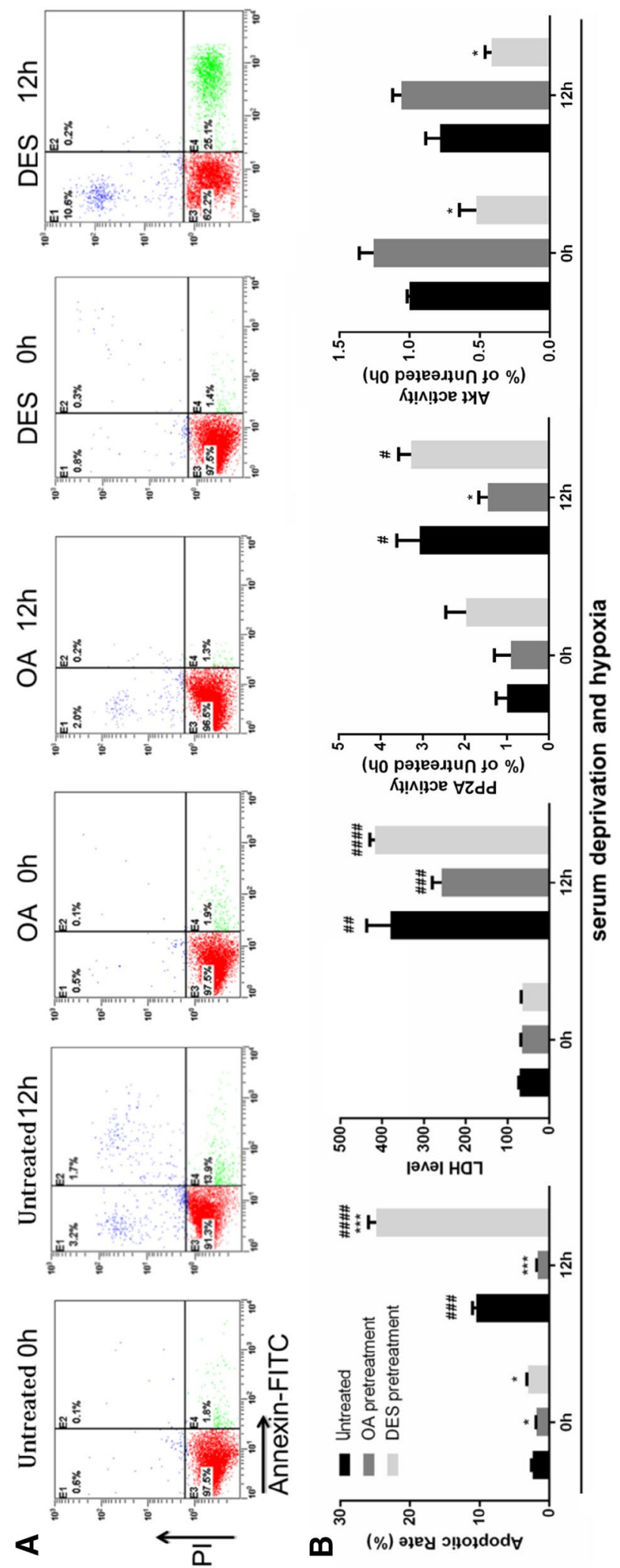

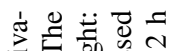

․․ㅇ क

䬺递

艺琎步

สิ ธี ซิ

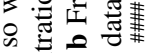

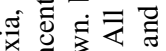

응 영-

霝

ส

딤으율

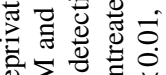

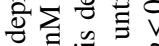

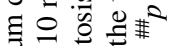

पे

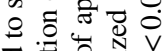

政

응 흠

$\Leftrightarrow$ ơ चै

于

Sิ

$\Xi \exists$ 类

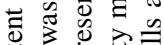

ख

ธ 0 记

월. 可艺

응

这的

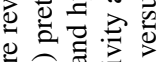

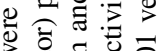

卷

.

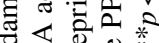

त 웡

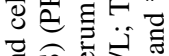

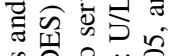

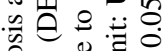

柁引

웅 웅

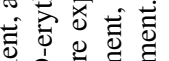

穴递

을

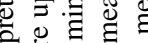

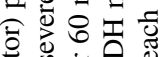

윰․․

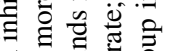

$\varangle$ 謨

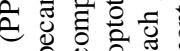

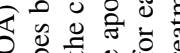

7 동

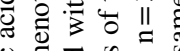

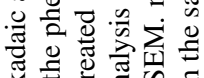

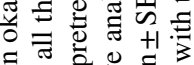

을월

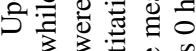

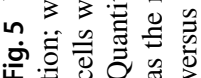



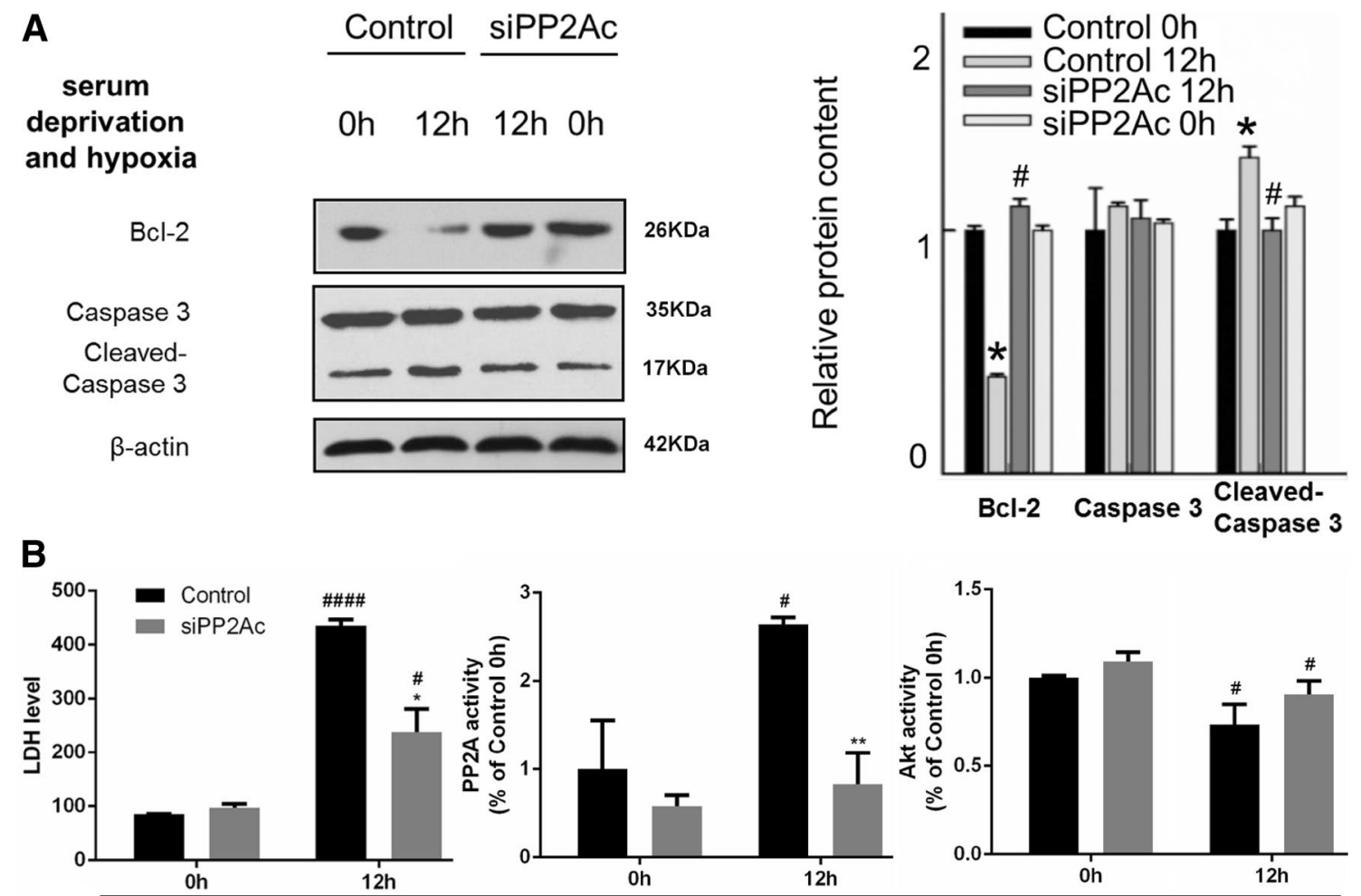

serum deprivation and hypoxia

Fig. 6 After PP2Ac knockdown, apoptosis and cell damage were reversed to an extent in L02 cells exposed to serum deprivation and hypoxia, so was Akt inactivation. L02 cells were transfected with GFP-siPP2Ac plasmid (the siPP2Ac group) or GFP-vector (the control group) for $48 \mathrm{~h}$. Then cells were serum deprived and cultured under hypoxic conditions. a Left: representative images of western blots for apoptotic markers Bcl-2, caspase- 3 and cleaved caspase 3 . Right: semi-quantitative analysis with $\beta$-actin as an internal control.

PP2A is a common event that is noted in several cancers that occurs as a result of the perturbed regulation of the cell growth and survival [43]. Many reports showed that PP2A is activated with cAMP/PKA [44, 45]; hypoxia can induce cAMP/PKA activation through HIF transcription factor [46]. Therefore, we speculated that enhanced PP2A activity in our brain death in vivo and in vitro model was due to the induction of hypoxia after brain death. With regard to Akt, PP2A has been shown to directly interact with this protein via the subunit B55 alpha [47]. PP2A inactivates Akt by dephosphorylation and in hepatoma cancers the reduced expression of PP2A B55 alpha subunit results in the increased activation of Akt and consequently increased growth and proliferation [48]. Previous studies demonstrated that the overexpression of eIF3I interacted with and activated the oncogenic Akt1 by preventing the PP2A-mediated dephosphorylation of Akt-1 in human hepatocellular carcinoma [24]. REDD1 enhances protein phosphatase 2A-mediated dephosphorylation of Akt, in order to repress mTORC1 signaling in 293T cells [25]. For the first time in the current study we demonstrated that
The results were normalized to the control $0 \mathrm{~h}$ group. b Left: LDH measurement; the unit: U/L. Middle and right: the PP2A or Akt activity measurement normalized to the control $0 \mathrm{~h}$ group. All data were expressed as the mean \pm SEM. $n=3$ for each group in each measurement. $* p<0.05$ and $* * p<0.01$ versus control cells at the same time; ${ }^{\#} p<0.05$ and ${ }^{\# \# \#} p<0.0001,12 \mathrm{~h}$ versus $0 \mathrm{~h}$, with the same transfection

the down regulation of Akt activity by PP2A results in apoptosis in liver cells in the brain-dead donors or in a similar in vivo brain death model.

In conclusion, the findings presented here disclose one of the underlying mechanisms for hepatocellular impairment after brain death, and imply potential targets for reducing hepatocyte apoptosis and improving hepatic graft quality, through PP2A inhibition or Akt activation. Studies in this field will help to prolong organ graft survival and lower the incidence of primary graft non-function or acute rejection.

\section{Materials and methods}

\section{Clinical DBD samples}

The study was approved by the ethics committee of the Zhongnan Hospital of Wuhan University. All patients or their legal representatives provided a written informed consent. 

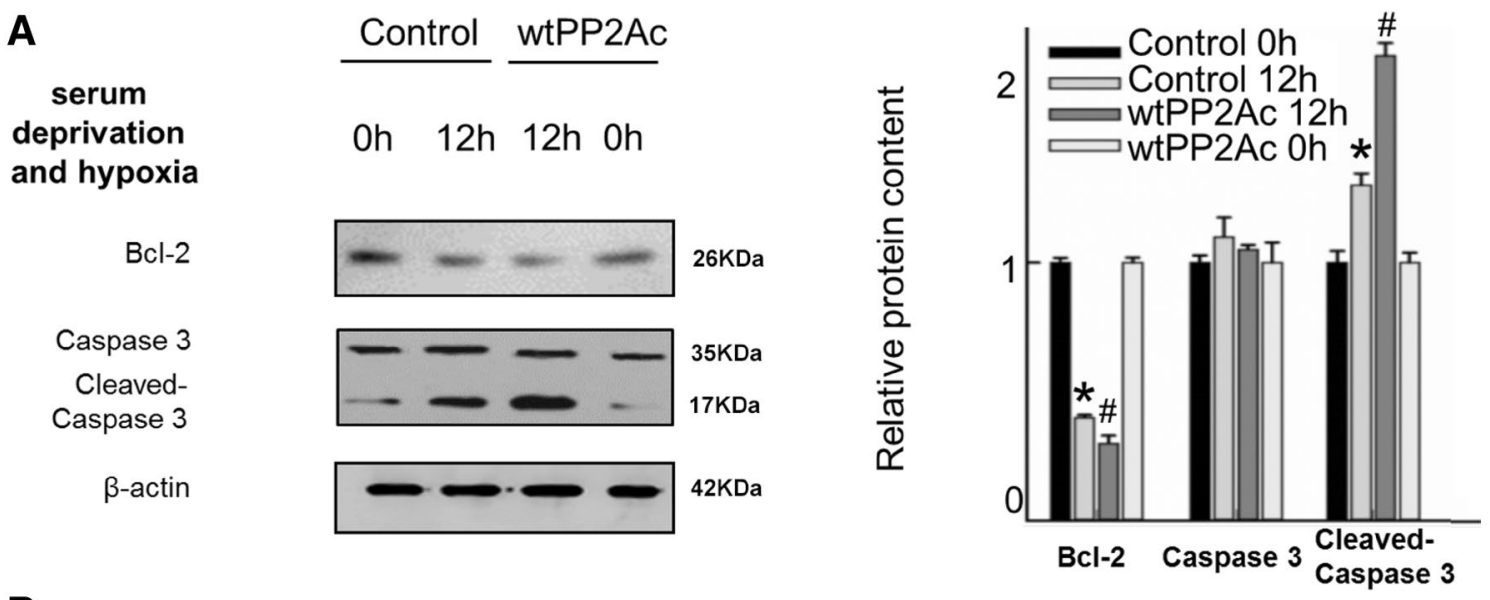

B

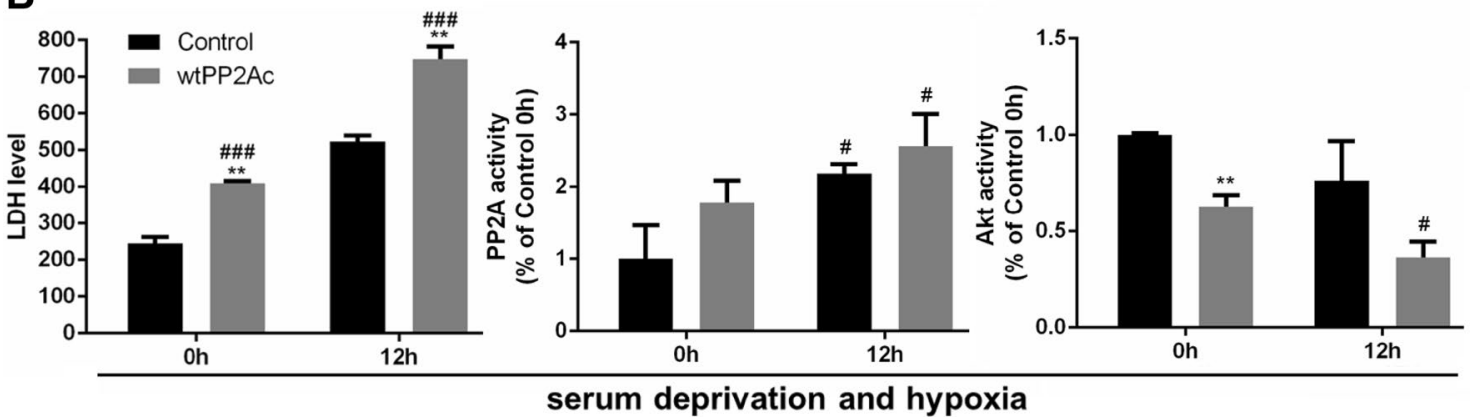

Fig. 7 After PP2Ac overexpression, apoptosis and cell damage became more severe in L02 cells exposed to serum deprivation and hypoxia, so did Akt inactivation. L02 cells were transfected with RFP-wtPP2A plasmid (the wtPP2A group) or RFP-vector (the control group) for $48 \mathrm{~h}$. Then cells were serum deprived and cultured under hypoxic conditions. a Left: representative images of western blots for apoptotic markers Bcl-2, caspase-3 and cleaved caspase 3 .
Right: semi-quantitative analysis with $\beta$-actin as an internal control. The results were normalized to the control $0 \mathrm{~h}$ group. b Left: LDH measurement; the unit: U/L. Middle and right: the PP2A or Akt activity measurement normalized to the control $0 \mathrm{~h}$ group. All data were expressed as the mean \pm SEM. $\mathrm{n}=3$ for each group in each measurement. $* p<0.05$ and $* * p<0.01$ versus control cells at the same time; ${ }^{\#} p<0.05$ and ${ }^{\# \# \#} p<0.001,12 \mathrm{~h}$ versus $0 \mathrm{~h}$, with the same transfection
Fig. 8 L02 cells were serum deprived and cultured under hypoxic conditions and the cell signaling markers were measured at $0,6,12$ and $18 \mathrm{~h}$ of that exposure. Left: representative western blots of the expression of the proteins $\mathrm{p} 38$, JNK, ERK and their phosphorylated counterparts. Right: semi-quantitative analysis of the expression of the proteins using $\beta$-actin as an internal control. All data were expressed as the mean \pm SEM. $n=3$ for each group in each measurement

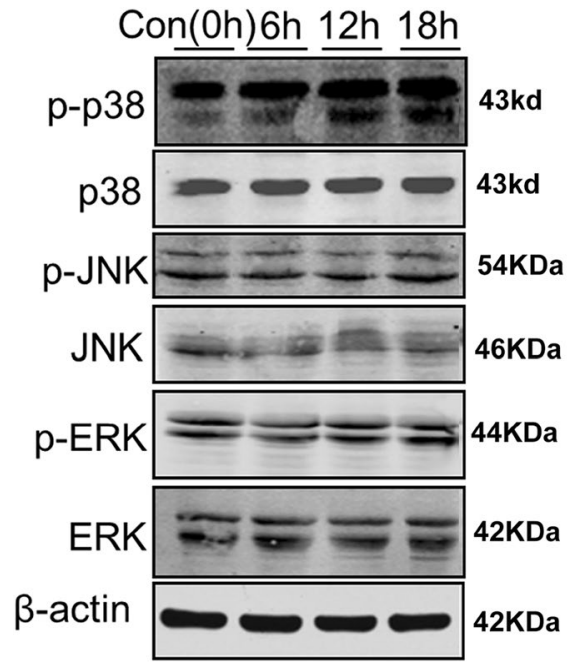

From February 2013 to March 2016, a total of 20 samples of DBD liver tissues were respectively collected from 20 donors at $2 \mathrm{~h}, 6 \mathrm{~h}$ or $12 \mathrm{~h}$ post brain death (Table S1) in the
Zhongnan Hospital of Wuhan University, Wuhan, China. The DBD liver tissues were extracted without perfusion. The tissues were suitable for transplantation, i.e., without any 


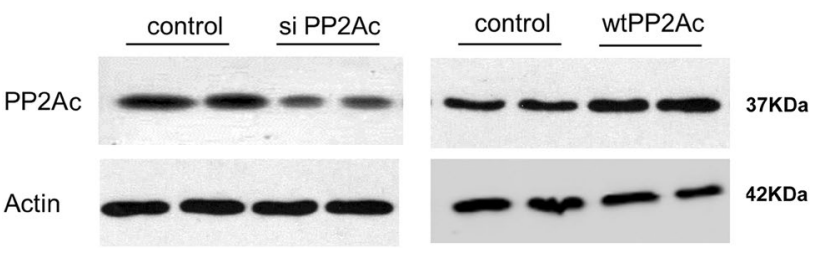

Fig. 9 The validation of the transfection efficiency of the wtPP2Ac plasmid and the siPP2Ac sequence in L02 cells using western blotting

lesions, cirrhosis, fatty liver disease, etc. The preservation solution was UW solution.

The liver tissues were homogenized in 10 volumes $(\mathrm{mL} / \mathrm{g}$ wet tissue) homogenate buffer containing $50 \mathrm{mM}$ Tris- $\mathrm{HCl}$, $\mathrm{pH}$ 7.0, $0.5 \mathrm{mM}$ Phenylmethylsulfonyl fluoride (PMSF), $2.5 \mathrm{mM}$ ethylenediaminetetraacetic acid (EDTA), $2.5 \mathrm{mM}$ ethylene glycol tetra acetic acid (EGTA), and 1:1000 protease inhibitor cocktail (Sigma-Aldrich Co., LLC., St. Louis, MO, USA). The tissue lysates were sonicated, and centrifuged at $16,000 \times g$ for $10 \mathrm{~min}$. The supernatants were used for the evaluation of the PP2A and Akt activity assays.

\section{Protein extraction and ITRAQ mass spectrometry analysis}

Liver samples after brain death for $2 \mathrm{~h}$ and $12 \mathrm{~h}$ were collected. Each sample (100 mg of protein) was digested with SDT solution and labeled with iTRAQ reagents (Applied Biosystems) according to the manufacturer's protocol. Subsequently, the labeled peptides were mixed equally and separated by 1260 Infinity HPLC (Agilent Technologies), followed by nano liquid chromatography tandem mass spectrometry using the Hybrid Quadrupole-Orbitrap mass spectrometer (Q-Exactive; Thermo Fisher Scientific) equipped with a nano-UPLC RSLC Ultimate 3000 (Dionex). Both peptide identification and quantitation were performed in an overall workflow in Proteome Discoverer software (version 1.4; Thermo Fisher Scientific) and searched against the UniProt human canonical sequence protein database (October 7, 2011; 56,869 entries) using Mascot search engine (version 2.4). For protein identification, $95 \%$ confidence was used. For quantitation and further validation experiments, all reported data were based on $95 \%$ confidence for protein identification as determined by Proteome Discoverer (Unique peptide $>1$ )

\section{Animals}

The study was carried out in strict accordance with the recommendations of the Guide for the Care and Use of Laboratory Animals of the National Institutes of Health. The protocol was approved by the Committee of the Ethics of Animal Experiments of Wuhan University 2014. All surgery was performed under sodium pentobarbital anesthesia, and all efforts were made to minimize suffering.

A total of 40 male New Zealand rabbits (weight 2800-3000 g, 3 months old) were obtained from the Center for Animal Experiments and ABSL-3 Laboratory of the Wuhan University (Wuhan, China). All animals were kept under standard laboratory conditions: $12 \mathrm{~h}$ of light and $12 \mathrm{~h}$ of darkness; lights were turned on at 6:00 a.m.; the temperature was kept at $22 \pm 2.0^{\circ} \mathrm{C}$; and water and food were ad libitum.

The DBD model was established in 30 rabbits as described previously $[28,29]$. The rabbits were deeply anesthetized with pentobarbital sodium at a dose of $40 \mathrm{mg} / \mathrm{kg}$ and then placed on the operating table. The femoral artery and vein cannulation, xiphoid separation and tracheal intubation, burr hole and catheter placement were carried out. The vital signs of the rabbits including electrocardiogram, blood pressure, respiratory functions, and electroencephalogram were monitored using a biological functional system, a rodent ventilator, and an intelligent temperature control instrument (Thai Union Technology, Co., Ltd., Chengdu, China). The intracranial pressure was increased as required until the occurrence of brain death. A total of ten rabbits were sacrificed respectively at $2 \mathrm{~h}, 4 \mathrm{~h}$, and $8 \mathrm{~h}$, following brain death.

The remaining ten rabbits received deep anesthesia without an increase in the intracranial pressure, and they were sacrificed $2 \mathrm{~h}$ following sham operation.

The liver tissues obtained from the animals were then processed as methods described for clinical samples, and used for the PP2A/Akt activity assays. Besides, after sonication, a part of tissue lysates was added with equal volume of phosphate inhibitor mixture $\left(2.0 \mathrm{mM} \mathrm{Na}_{3} \mathrm{VO}_{4}\right.$ and $100 \mathrm{mM}$ $\mathrm{NaF}, \mathrm{pH}$ 7.0) and stored at $-80^{\circ} \mathrm{C}$ for Western blotting.

\section{Cell culture}

Human liver cell line L02 was obtained from Kunming Institute of Zoology (Chinese Academy of Sciences, Kunming, China). The cells were grown to $70-80 \%$ confluence in sixwell culture plates in Dulbecco's Modified Eagle's medium (Gibco (Life Technologies), CA, USA) supplemented with $10 \%$ fetal bovine serum (FBS), 100 units $/ \mathrm{mL}$ penicillin, and $0.1 \mathrm{mg} / \mathrm{mL}$ streptomycin.

The L02 cells were exposed to small molecule treatment or transfected with specific plasmids (see detailed description below). Then the cells were cultured in serum-free DMEM/low glucose medium (HyClone, USA) and placed in a tri-gas incubator (thermo fisher 3131, Waltham, MA USA) which can control the oxygen concentration at $1 \%$, to make ischemic and hypoxic conditions mimicking adverse environment of liver in BD donors [30]. The specific processing times were indicated in the corresponding figures. 
After different treatments, some of cells were used for flow cytometry analysis, cell viability analysis and lactate dehydrogenase (LDH) measurement. The remaining cells were harvested and suspended in buffer containing $2.0 \mathrm{mM}$ EGTA, $0.5 \mathrm{mM}$ PMSF, $5 \mathrm{mM}$ EDTA, $150 \mathrm{mM} \mathrm{NaCl}, 50 \mathrm{mM}$ Tris- $\mathrm{HCl}$ (pH 7.4), 1.0\% Triton X-100, and a protease inhibitor cocktail (1:200). The cell lysates were sonicated and divided into three parts. The first part was mixed with equal volume of phosphate inhibitor mixture $\left(2.0 \mathrm{mM} \mathrm{Na}_{3} \mathrm{VO}_{4}\right.$ and $100 \mathrm{mM} \mathrm{NaF}, \mathrm{pH} 7.0$ ) and stored at $-80^{\circ} \mathrm{C}$ for Western blotting. The rests were centrifuged at $16,000 \times g$ for $10 \mathrm{~min}$, and the supernatants were used for PP2A and Akt activity assay.

\section{Small molecule pretreatment}

L02 cells were pretreated with specific concentrations of small molecules at 60 min time periods. The Akt inhibitor MK-2206 (Selleckchem, USA) and the PP2A inhibitor OA (Santa cruz, USA) were incubated with L02 cells at a concentration of $10 \mathrm{nM}$. The Akt activator SC79 (TOCRIS bioscience, Missouri, USA) and the PP2A activator DES (San Diego, CA, USA) were incubated with L02 cells at concentrations of $4 \mu \mathrm{g} / \mathrm{mL}$ and $5 \mu \mathrm{M}$, respectively.

\section{Cell transfection}

The plasmids carrying the EGFP-siPP2Ac (a small interfering RNA construct designed specifically for $p p 2 a c$ ) and the DsRed-wild-type (wt) PP2Ac were kindly provided by Professor Jianzhi Wang (Tongji Medical College, HuaZhong University of Science and Technology, Wuhan, China). L02 cells were transfected with EGFP-siPP2A or DsRedwtPP2Ac plasmids using Lipofectamine 2000 according to the manufacturer's instruction (Invitrogen, San Diego, CA, USA). The plasmids that contained solely fluorescent proteins were used as the controls. Following $48 \mathrm{~h}$ of transfection, the cells were used for further analyses.

\section{Flow cytometry analysis}

The cellular apoptosis and necrosis were assessed using the Annexin V-FITC apoptosis kit (Franklin Lakes, NJ, USA) according to the manufacturer's instructions. The cells were digested with trypsin, centrifuged at $1000 \times g$ for $5 \mathrm{~min}$, and incubated with $5 \mu \mathrm{L}$ Annexin V and $5 \mu \mathrm{L}$ PI for $10 \mathrm{~min}$ at room temperature in the dark. The cells from each sample were then identified using a FacsCalibur flow cytometer (BD Biosciences). The data were analyzed using CELLQuest software (BD). The experiments were repeated at least three times.

\section{Cell viability analysis}

The cell viability was assessed with the Cell Counting Kit-8 detection kit (CCK8) (Dojindo Laboratories, Kumamoto, Japan) according to the manufacture's protocol. A total of $1 \times 10^{5}$ cells were cultured in 96 -well plates. The cells were performed with different treatments, and then $100 \mu \mathrm{L} 10 \%$ CCK8 solution was added in each well. The samples were incubated at $37^{\circ} \mathrm{C}$ for $1 \mathrm{~h}$. The absorbance was measured at $450 \mathrm{~nm}$ using a microplate reader (VersaMax, Molecular Devices, USA). The experiments were repeated at least three times.

\section{Lactate dehydrogenase (LDH) measurement}

The cell medium was collected for the LDH measurement using the AU5400 Clinical Chemistry System (beckman coulter, USA), and the results were expressed in the unit of $\mathrm{U} / \mathrm{L}$. The experiments were repeated at least three times.

\section{Western blotting}

The liver tissue lysates (from clinical samples or modeling rabbits) or the L02 cell lysates were electrophoresized in 10\% SDS-polyacrylamide gel and the proteins were transferred to nitrocellulose membranes. The membranes were incubated with specific antibodies. Primary antibodies against: pSer473 Akt, Bcl-2, Caspase 3, CleavedCaspase 3, p38, p-p38, JNK, p-JNK, ERK, p-ERK were from cell signaling (Danvers, MA, USA); total Akt was from Proteintech (Chicago, UK); total PP2Ac was from Millipore (Billerica, MA, USA); $\beta$-actin was from Abcam (Cambridge, UK). Secondary antibodies conjugated to I IRDye ${ }^{\mathrm{TM}} 800 \mathrm{CW}$ were from Licor Biosciences (Lincoln, NE, USA). The results were visualized using the Odyssey Infrared Imaging System (LI-COR Biosciences, Lincoln, NE, USA).

\section{PP2A/Akt activity assay}

The supernatants of the liver tissue lysates (from clinical samples or modeling rabbits) or L02 cell lysates were prepared as described above. The activity of PP2A in the supernatants was detected using the phosphatase kit V2460 (Promega, Madison, WI, USA) according to the manufacturer's protocol, with the results expressed as nmol phosphorus/ $\mathrm{mg} / \mathrm{min}$. The activity of Akt was detected using the colorimetric method quantity detecting kit (Genmed Scientifics Inc., Arlington, MA, USA) according to the manufacturer's protocol, with the results expressed as $\mu \mathrm{mol} \mathrm{NADH} / \mathrm{mg} / \mathrm{min}$. 


\section{Statistical analysis}

The data are expressed as the mean \pm standard error of measurement (SEM) and analyzed using SPSS 16.0 (SPSS Inc., Chicago, IL, USA). The one-way analysis of variance (ANOVA) procedure followed by the Fisher's Least Significant Difference post hoc test (LSD) and Student's $t$ test were used to determine the differences among the groups. The statistical differences were considered significant if the $p$ value was $<0.05$.

Acknowledgements This work was supported by the National Natural Science Foundation of China (Nos.: 81700574, U140322).

Author contributions $\mathrm{YX}$ and JL conceived and planned the experiments. $\mathrm{KH}, \mathrm{LZ}$ and $\mathrm{YZ}$ carried out the experiments. YW took the lead in writing the manuscript. All authors provided critical feedback and helped shape the research, analysis and manuscript.

\section{Compliance with ethical standards}

Conflict of interest No conflicts of interest, financial or otherwise, are declared by the authors.

Open Access This article is distributed under the terms of the Creative Commons Attribution 4.0 International License (http://creativecommons.org/licenses/by/4.0/), which permits unrestricted use, distribution, and reproduction in any medium, provided you give appropriate credit to the original author(s) and the source, provide a link to the Creative Commons license, and indicate if changes were made.

\section{References}

1. Kim WR, Smith JM, Skeans MA et al (2014) OPTN/SRTR 2012 annual data report: liver. Am J Transplant 14(suppl 1):69-96

2. Matas AJ, Smith JM, Skeans MA et al (2014) OPTN/SRTR 2012 annual data report: kidney. Am J Transplant 14(suppl 1):11-44

3. Colvin-Adams M, Smithy JM, Heubner BM et al (2014) OPTN/ SRTR 2012 annual data report: heart. Am J Transplant 14(suppl 1):113-138

4. Abt PL, Praestgaard J, West S, Hasz R (2014) Donor hemodynamic profile presages graft survival in donation after cardiac death liver transplantation. Liver Transpl 20:165-172

5. Damman J, Hoeger S, Boneschansker L et al (2011) Targeting complement activation in brain-dead donors improves renal function after transplantation. Transpl Immunol 24:233-237

6. Perk S, Izamis ML, Tolboom H et al (2011) A metabolic index of ischemic injury for perfusion-recovery of cadaveric rat livers. PLoS ONE 6:e28518

7. Saito Y, Goto M, Maya K et al (2010) Brain death in combination with warm ischemic stress during isolation procedures induces the expression of crucial inflammatory mediators in the isolated islets. Cell Transplant 19:775-782

8. Ishikawa N, Yagisawa T, Kimura T et al (2013) Kidney transplantation of living unrelated and ABO-incompatible donorrecipient combinations. Transplant Proc. 45:1242-1244
9. McAdams-DeMarco MA, Isaacs K, Darko L et al (2015) Changes in frailty after kidney transplantation. J Am Geriatr Soc 63:2152-2157

10. Adrie C, Monchi M, Fulgencio JP et al (2010) Immune status and apoptosis activation during brain death. Shock 33:353-362

11. Cao S, Wang T, Yan B, Lu Y, Zhao Y, Zhang S (2014) Brain death is associated with endoplasmic reticulum stress and apoptosis in rat liver. Transplant Proc 46:3297-3302

12. Daemen MA, van't Veer C, Denecker G et al (1999) Inhibition of apoptosis induced by ischemia-reperfusion prevents inflammation. J Clin Invest 104:541-549

13. Zhang SJ, Wang T (2011) The influence of brain death on donor liver and the potential mechanisms of protective intervention. Front Med 5:8-14

14. Sangodkar J, Farrington CC, McClinch K, Galsky MD, Kastrinsky DB, Narla G (2016) All roads lead to PP2A: exploiting the therapeutic potential of this phosphatase. FEBS J 283:1004-1024

15. Virshup DM, Shenolikar S (2009) From promiscuity to precision: protein phosphatases get a makeover. Mol Cell 33:537-545

16. Wlodarchak N, Xing Y (2016) PP2A as a master regulator of the cell cycle. Crit Rev Biochem Mol Biol 51:162-184

17. Shi Y (2009) Serine/threonine phosphatases: mechanism through structure. Cell 139:468-484

18. Meng G, Wang W, Chai K, Yang S, Li F, Jiang K (2015) Combination treatment with triptolide and hydroxycamptothecin synergistically enhances apoptosis in A549 lung adenocarcinoma cells through PP2A-regulated ERK, p38 MAPKs and Akt signaling pathways. Int J Oncol 46:1007-1017

19. Arriazu E, Pippa R, Odero MD (2016) Protein phosphatase 2A as a therapeutic target in acute myeloid leukemia. Front Oncol 6:78

20. Xin M, Deng X (2006) Protein phosphatase 2A enhances the proapoptotic function of Bax through dephosphorylation. J Biol Chem 281:18859-18867

21. Humphrey SJ, James DE (2012) Uncaging akt. Sci Signal 5:20

22. Manning BD, Cantley LC (2007) AKT/PKB signaling: navigating downstream. Cell 129:1261-1274

23. Yang J, Wu Z, Renier N et al (2015) Pathological axonal death through a MAPK cascade that triggers a local energy deficit. Cell 160:161-176

24. Wang YW, Lin KT, Chen SC et al (2013) Overexpressed-eIF3I interacted and activated oncogenic Akt1 is a theranostic target in human hepatocellular carcinoma. Hepatology 58:239-250

25. Dennis MD, Coleman CS, Berg A, Jefferson LS, Kimball SR (2014) REDD1 enhances protein phosphatase 2A-mediated dephosphorylation of Akt to repress mTORC1 signaling. Sci Signal 7:68

26. Liu GP, Wei W, Zhou X et al (2012) I(2)(PP2A) regulates p53 and Akt correlatively and leads the neurons to abort apoptosis. Neurobiol Aging 33:254-264

27. Zhang QJ, Holland WL, Wilson L et al (2012) Ceramide mediates vascular dysfunction in diet-induced obesity by PP2A-mediated dephosphorylation of the eNOS-Akt complex. Diabetes 61:1848-1859

28. Du B, Li L, Zhong Z et al (2014) Brain death induces the alteration of liver protein expression profiles in rabbits. Int J Mol Med 34:578-584

29. Pratschke J, Wilhelm MJ, Kusaka M, Laskowski I, Tilney NL (2000) A model of gradual onset brain death for transplant-associated studies in rats. Transplantation 69:427-430

30. Tu Q, Xiong Y, Fan L et al (2016) Peroxiredoxin 6 attenuates ischemia and hypoxiainduced liver damage of braindead donors. Mol Med Rep 13:753-761

31. Jo H, Mondal S, Tan D et al (2012) Small molecule-induced cytosolic activation of protein kinase Akt rescues ischemia-elicited neuronal death. Proc Natl Acad Sci USA 109:10581-10586 
32. Guo Y, Deng Y, Li X et al (2016) Glutaminolysis Was induced by TGF-beta1 through PP2Ac regulated Raf-MEK-ERK signaling in endothelial cells. PLoS ONE 11:e0162658

33. Chalfant CE, Szulc Z, Roddy P, Bielawska A, Hannun YA (2004) The structural requirements for ceramide activation of serinethreonine protein phosphatases. J Lipid Res 45:496-506

34. Liu X, Wang B, Zhang $X$ et al (2016) Liver transplantation using donation after brain and cardiac death: a single-center experience in China. Transplant Proc 48:1879-1886

35. Scalea JR, Redfield RR, Foley DP (2016) Liver transplant outcomes using ideal donation after circulatory death livers are superior to using older donation after brain death donor livers. Liver Transplant 22:1197-1204

36. Xu J, Sayed BA, Casas-Ferreira AM et al (2016) The impact of ischemia/reperfusion injury on liver allografts from deceased after cardiac death versus deceased after brain death donors. PLoS ONE 11:e0148815

37. Weiss S, Kotsch K, Francuski M et al (2007) Brain death activates donor organs and is associated with a worse I/R injury after liver transplantation. Am J Transplant 7:1584-1593

38. Sanchez-Fructuoso A, Naranjo Garcia P, Calvo Romero N et al (2007) Effect of the brain-death process on acute rejection in renal transplantation. Transplant Proc 39:2214-2216

39. Novitzky D, Cooper DK, Rosendale JD, Kauffman HM (2006) Hormonal therapy of the brain-dead organ donor: experimental and clinical studies. Transplantation 82:1396-1401

40. Kotsch K, Francuski M, Pascher A et al (2006) Improved longterm graft survival after HO-1 induction in brain-dead donors. Am J Transplant 6:477-486

41. Van Der Hoeven JA, Moshage H, Schuurs T, Nijboer M, Van Schilfgaarde R, Ploeg RJ (2003) Brain death induces apoptosis in donor liver of the rat. Transplantation 76:1150-1154
42. Ruvolo PP (2016) The broken "Off" switch in cancer signaling: PP2A as a regulator of tumorigenesis, drug resistance, and immune surveillance. BBA Clin 6:87-99

43. Hein AL, Seshacharyulu P, Rachagani S et al (2016) PR55alpha subunit of protein phosphatase 2A supports the tumorigenic and metastatic potential of pancreatic cancer cells by sustaining hyperactive oncogenic signaling. Cancer Res 76:2243-2253

44. Ahn JH, McAvoy T, Rakhilin SV, Nishi A, Greengard P, Nairn AC (2007) Protein kinase A activates protein phosphatase 2A by phosphorylation of the B56delta subunit. Proc Natl Acad Sci USA 104(8):2979-2984

45. Feschenko MS, Stevenson E, Nairn AC, Sweadner KJ (2002) A novel cAMP-stimulated pathway in protein phosphatase $2 \mathrm{~A}$ activation. J Pharmacol Exp Ther 302(1):111-118

46. Simko V, Iuliano F, Sevcikova A et al (2017) Hypoxia induces cancer-associated cAMP/PKA signalling through HIF-mediated transcriptional control of adenylyl cyclases VI and VII. Sci Rep 7(1): 10121

47. Wang J, Wang Z, Yu T et al (2016) Crystal structure of a PP2A B56-BubR1 complex and its implications for PP2A substrate recruitment and localization. Protein Cell 7:516-526

48. Lei N, Peng B, Zhang JY (2014) CIP2A regulates cell proliferation via the AKT signaling pathway in human lung cancer. Oncol Rep 32:1689-1694

Publisher's Note Springer Nature remains neutral with regard to jurisdictional claims in published maps and institutional affiliations. 